Portland State University

PDXScholar

11-30-1984

\title{
An Analysis of the Affects of Crisis on the Decision Making Practice of a Dialysis Program: a Case Study
}

James Christopher Farley

Portland State University

Follow this and additional works at: https://pdxscholar.library.pdx.edu/open_access_etds

Part of the Health Communication Commons

Let us know how access to this document benefits you.

\section{Recommended Citation}

Farley, James Christopher, "An Analysis of the Affects of Crisis on the Decision Making Practice of a Dialysis Program: a Case Study" (1984). Dissertations and Theses. Paper 3434.

https://doi.org/10.15760/etd.5317

This Thesis is brought to you for free and open access. It has been accepted for inclusion in Dissertations and Theses by an authorized administrator of PDXScholar. Please contact us if we can make this document more accessible: pdxscholar@pdx.edu. 
AN ABSTRACT OF THE THESIS OF James Christopher Farley for the Master of Science in Communication presented November 30,1984

Title: An Analysis of the Affects of Crisis on the Decision Making Practice of a Dialysis Program: A Case study APPROVED BY MEMBERS OF THE THESIS COMMITTEE:

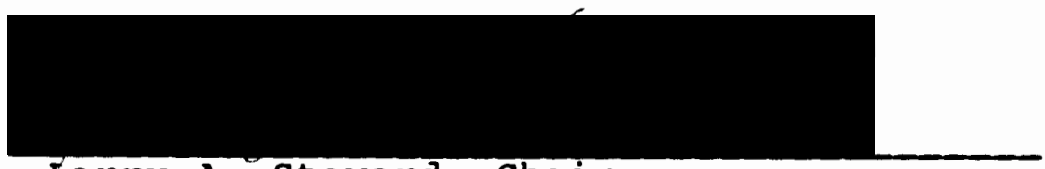

Larry A. Steward, Chairman

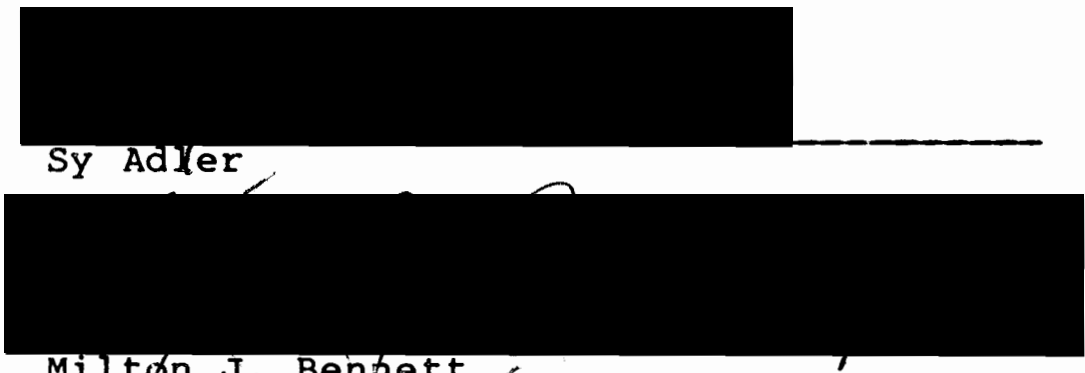

Milton J. Benfiett

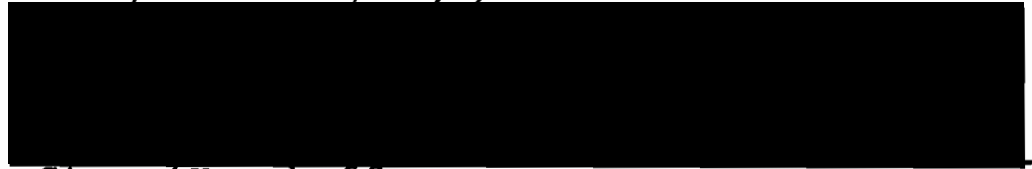

Steve Kosokoff

In 1982 the Health Care Finance Administration mandated changes in the mechanism and financing of the End Stage Renal Disease (ESRD) Program by the provisions of the Omnibus Budget Reconciliation Act. These changes in finances and procedures became effective August 1,1983 and have created a state of crisis for ESRD facilities program wide. This study analyzes a large non-profit dialysis program and how its decision making practices were affected 
by the change in Medicare laws. Application of decision theory in health care provides a basis for this study on the affects of crisis on decision making.

This study reports on the application of decision theory to 12 members of a dialysis program through the use of a survey and an interview. This application resulted in the determination of five salient issues which contribute to identifying decision making practices. In addition, this application determined the overall decision method, the participant's perception of the process, and the perceived affects of the crisis on patient care. To determine the decision making methods employed prior to and following the "crisis" date two methods were used, a survey and a follow-up interview. These two methods served to address the following:

A. The Decision Making Survey addressed the characteristics of the decision making process. These characteristics were then applied to a participative decision making continuum.

B. The Decision Making Interview determined the validity of the survey responses, acted as a second method for determining decison making 
characteristics, and addressed the secondary issues of this study, i.e., decision alternatives and patient care.

The results of the data were analyzed using a descriptive approach. The study showed how one dialysis program responded to the Medicare crisis by employing a participative decision making style. Further, the relevancy of those results is discussed in terms of its medical and social implications. 


\section{An Analysis of the Affects of Crisis on the Decision Making Practice of a Dialysis Program: A Case Study}

by

James Christopher Farley

A thesis submitted in partial fulfillment of the requirements for the degree of

\section{MASTER OF SCIENCE in SPEECH COMHUNICATION}

Portland State University

1985 


\section{TO THE OFFICE OF GRADUAGE STUDIES AND RESEARCH:}

The members of the Committee approve the thesis of

James Christropher Farley presented November 30, 1984.

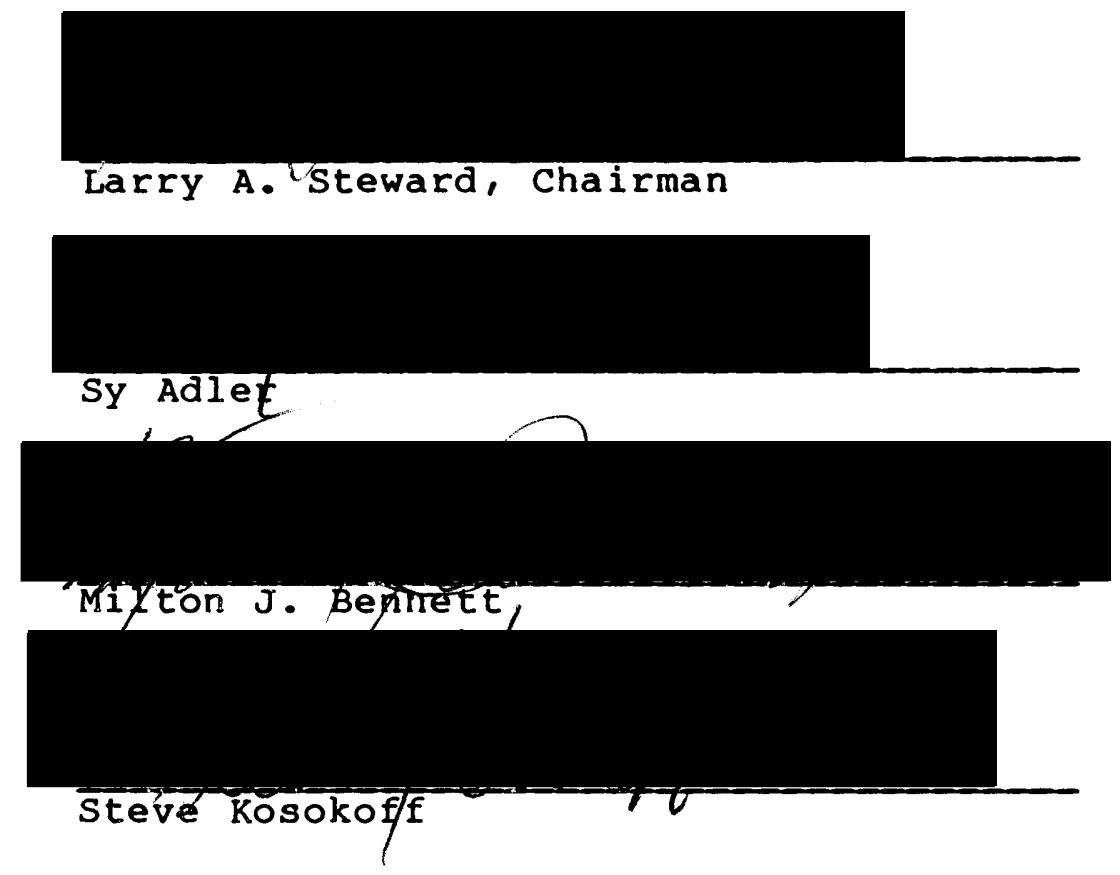

APPROVED :

Theodore G. Grove, Chair, Department of Speech Communication Jym F. Feath, Acting Dean of Graduate Studies and Research 
TABLE OF CONTENTS

PAGE

LIST OF TABLES • • • • • • • • • • • • • • • • • • • v

LIST OF FIGURES . . . . . . . . . . . . . . vi

CHAPTER

I INTRODUCTION . . . . . . . . . . . 1

Significance of the Problem

Purposes of the Study . . . . . .

II COMMUNICATION THEORY AND REVIEW OF

THE LITERATURE . . . . . . . . . . 10

Organizational and Decision Theory . . 10

Decision Making Under Uncertainty . . 15

The Affects of Crisis

Member Participation in Decision Making

Decision Making Continuum . . . . .

III METHODS . . . . . . . . . . . 23

The Good Samaritan Dialysis Program • . 23

Step I: Decision Making Survey . . . 28

Relevance of the Survey to the Decision Making Continuum

Step II: Decision Making Interview .

Relevance of the Interview to

the Study

Limitations of the Study . . . . . . 
IV DATA ANALYSis AND RESUlts . . . . . . . 40

Reliability and validity . . . . . 41

Application to Decision Theory . . . . 42

Application to Secondary Issues . . . 59

$\mathrm{V}$ CONCLUSIONS AND RECOMmENDATIONS . . . . . 61

Conclusions from the Data . . . . . 61

Participative Decision Making

Analysis of a Power Conflict

Recommendations for the GSH\&MC

Dialysis Program . . . . . . . 64

Recommendations for Further

Research ............. 67

SELECTED BIBLIOGRAPHY . . . . . . . . . . . . 69

APPENDIX A . . . . . . . . . . . . . 73

APPENDIX B . . . . . . . . . . . . . . . 80 


\section{LIST OF TABLES}

I Organization of Decision Making Continuum . • . . . • . . . . . . .

II Formal Organizational Chart of the

GSH\&MC Dialysis Program . . . . . . .

II Decisions Made by the GSH\&MC Dialysis

$$
\text { Program During the Crisis Period . . . }
$$




\section{LIST OF FIGURBS}

1. Ranking of Decisions from the Decision Making Survey - . . . . . . . . • .

2. Decision Ranked as Most Important from Decision Making Survey . . . . . . . 


\section{CHAPTER I}

\section{INTRODUCTION}

There is an unquestionable alteration in the dynamics of the process of decision making when an organization is faced with crisis or change. The health care industry is no exception to this pattern of organizational behavior, especially in the wake of a Medicare funding cut. This paper examines how a hospital-based dialysis program altered its decision making practices as a result of the Medicare crisis.

End-Stage Renal Disease (ESRD) refers to an affliction of those people with kidney failure who are dependent on dialysis for 1 ife support. In 1972 Congress extended Medicare to all victims of End-Stage Renal Disease regardless of age. At that time it was projected that the program would cost $\$ 200$ million in 1976 ; four years later the cost for the ESRD program was $\$ 400$ million, twice that which was anticipated. While the costs of the ESRD program had been large, they grew proportionately with the lives extended.1 During the 1970's and early 1980's, the program relied on a combination of cost-based reimbursements and Medicare-fixed fee assessments, or "screen" charges, as the

1The ESRD Program is funded primarily by Medicare, although Medicaid, private insurers, and other payers also contribute to the program. 
mechanism for regulating payment and care. For nearly eleven years this mechanism was effective at regulating and maintaining the ESRD Program.

Although the above mentioned mechanisms were effective at controlling finance and governance issues, political forces sought to change this method. In 1981 the Health Care Finance Administration ( $\mathrm{HCFA}$ ) mandated changes in the mechanism and financing of the ESRD Program by the provisions of the Omnibus Budget Reconciliation Act (9735). These provisions instituted the use of a reimbursement schedule, thereby severly reducing program funding and generating considerable "red tape" for obtaining reimbursement for an ESRD facility. These changes in Medicare law were eventually published in May, 1983 in the Federal Register and became effective August 1, 1983. These changes in finances and procedures have created a state of crisis for ESRD facilities program wide.

The implementation of the Omnibus Budget Reconciliation Act has resulted in both a financial and bureaucratic crisis for ESRD Programs. This crisis has been born-out to the extent that a coalition of groups, including the Renal Physicians Association (RPA) and the National Association of Patients on Hemodialysis and Transplantation cited the closure of nine dialysis centers in December of 1983 as evidence of failure of the new Medicare 
regulations. 2 In February, the RPA documented the closure of ten additional centers due to the Medicare changes. 3 There is no doubt that the scope of this crisis is great. Due to the enormity of the crisis the definition of the word crisis must be confined to meet the needs of this study. For purposes of this study crisis will be defined as a state in which the relevance of variables is uncertain, when the relationships that exist among them is unknown, and when it is not known which outcomes can occur and which outcomes are associated with each decision alternative, thus creating an uncertain environment. 4

Daily, the administrators, physicians, and managers of these facilities make decisions which have an impact on the patients of their programs. During the past decade considerable interest has arisen over the processes of decision making and the application of theory to the health delivery system. Krischner (1980) has identified some 110 decision analytic applications to health care. While this is a relatively new area of study, annotated research

pp. ${ }^{2}$ Contemporary Dialysis, Vol -4 , No. 2, Dec. 1983,

${ }^{3}$ Contemporary Dialysis, Vol . 5, No. 2, Feb. 1984, pp. $10-15$.

${ }_{4}^{4}$ Adapted from Ronald Ebert and T. Mitchell. Organizational Design Process (N.Y.:Crane, Russak, and Co., Inc., 1975), pp. 135-39. 
studies collected by Kaplan (1977) demonstrated the use of four group process decision making applications common in the health care setting: Nominal Group Technique, Brainstorming, Delphi Technique, and Estimate-Talk-Estimate Technique. Further, as crisis or change occurs in a given setting, there is an alteration in the dynamics of the decision making process (March, 1982). (C.F. review of literature.) As described above, dialysis facilities across the country are experiencing a period of significant change and financial crisis.

To maintain an effective decision making environment during this crisis, health care professionals require a clear understanding of the effects crisis has on decision making practices, and perhaps an alternative approach to decision making. Such an understanding could result in more immediate, effective (profitable), and satisfying decisions, and is more likely to reflect the collective social morality for which health care professionals are responsible. The intention of this paper is to analyze a large non-profit dialysis program and determine how its decision making practices were effected by the change in Medicare laws, i.e., a financial and bureaucratic crisis. This is a case study of a single dialysis program and is not meant to represent all dialysis programs or health care in general. Rather, this study addresses the question of how program 
administrators of a dialysis center responded to high levels of uncertainty regarding the "rules" of Medicare law changes and the relationship between the laws, decisions and potential outcomes. 
PURPOSE

As seen daily in our newspapers there is presently considerable recognition in our society that health care costs are one of our greatest economic concerns.

Reimbursement for dialysis patients and their care is one of the greatest expense of the annual Medicare budget. Total expenditures for dialysis patients for fiscal year 1983 was 2. 1 Billion according to the HFCA Budget office, and is projected to be 2.2 Billion for 1984.5 In fact, the Secretary of the Department of Health and Human Services (Margaret Heckler), in a statement before the Senate Committee on Finance, said that she was implementing "the third largest budget in the world."6 It is easy to see why the Department of Health and Human Services felt it necessary to make changes in the Medicare program. These changes primarily consisted of Diagnostic Related Groupings (DRG's) and a Dialysis Rimbursement Schedule. Hospitals are reimbursed for services to Medicare patients on the basis of the patient's discharge diagnosis and the payment grouping Medicare has given it, i.e., DRG's. Likewise, Dialysis Programs are reimbursed on the basis of a

\footnotetext{
p. 16 .

${ }^{5}$ Contemporary Dialysis, Vol. 5, No. 3, March 1984, ${ }^{6}$ Contemporary Dialysis, Vol . 4, No. 4, April 1983, pp. $13-17$.
} 
formula encompassing the cost of supplies, staff, etc., and adjusted to the appropriate economic conditions of a given region. Presently, "non-profit" programs are the corner-stone of our health care delivery system and as a result are a discernible cause of rising health care costs. What then has been the impact of these new laws on the administration and operation of hosptials and dialysis programs, in particular those which are categorized as non-profit?

The intention of this study is to look at a dialysis program that is a part of a large non-profit, religion affiliated hospital and medical center with regard to the impact that the aforementioned Medicare changes have had on the decision making practices of the program. The intent is to focus specifically on the decision making process, options and channels of communication as they took place prior to and following the implementation of the Medicare law changes. It is my hypothesis that the crisis, the institution of the Dialysis Reimbursement schedule by Medicare, will influence the decision making practices of the program's administrators, physicians, and managers such that a more participative/collaborative approach will be used. The alternative is that the crisis did not have an effect on decision making practices, or that decision making became more autocratic. 
The research questions this study will address are as follows :

1. Did the Medicare crisis affect the decision making process, options, and techniques employed by a non-profit dialysis program as perceived by the participants in the decisions.

a. How, if applicable, were the decision making techniques employed prior to the crisis rendered ineffective.

b. Did the decision makers opt for an approach that was more or less participative in nature.

2. Does the crisis encourage the use of outside social sources of knowledge, e.g., specialists, consultants; if so, do the decision makers perceive a better solution from utilizing these sources. 7

3. What has been the perceived affect of the crisis on the availability and quality of patient care.

These research questions culminated in nine specific questions addressing the characteristics of decision making and were presented to the participants in a survey questionnaire. The remainder of this paper will be organized as follows. Chapter II will address relevant Comminication Theory and a Review of the Literature. It is in this

7Adapted from A. Collins and Guetzkow, A Social Psychology of Group Processes for Decision Making. (London: John Wiley \& Sons, Inc., 1964), pp. 55. 
chapter where the theoretical rationale for the Decision Making Continuum is discussed. Chapter III will describe the methods used in this study. Specifically, this chapter describes the Dialysis Program and the criteria used for selecting participants, the Decision Making Survey, and the Interview process respectively. A descriptive analysis of the data is contained in Chapter IV, addressing the characteristics of the program's decision making processes as they were affected by the crisis. Lastly, Chapter V contains the conclusions of the study, followed by recommendations for the program and future research. 
CHAPTER II

\section{COMMUNICATION THEORY AND \\ REVIEW OF THE LITERATURE}

The purpose of this chapter is to examine the communication theory relevant to this study through a review of the literature. Specifically, this chapter will discuss: organizational structure, decision making theory, the need for participation, the effects of crisis on decision making, decision making theory in health care, and the application of theory to this study.

The Weberian model of bureaucracy has strongly. influenced the concept of the Classical/Hierarchial Organizational structure. More current work on the Classical Organizational structure has been done by $\mathrm{Blau}$ and Schoenherr (1971). At the heart of the Hierarchical Organizational structure is Weber's notion of power, which he defines as the ability to induce acceptance or orders. This approach is characterized by structuralism based on power and purposive activity. 8 Most communication theorists would concur that organizational design and decision making may be viewed on a continuum, with the Weber

8Max Weber, The Theory of Social and Economic Organizations, Trans. A. Henderson and Talcott Parsons (N.Y.: Oxford Univ. Press, 1947), pp. 150-152. 
model at the far left or autocratic end. Found at the opposite end of this continuum is the Human Relations Structure, which is characterized by intraorganizational activity and extended boundries. Theorists subscribing to this theory include Katz and Kahn (1966) and Zald (1970). Just as the Classical approach stresses structure and the Human Relations emphasizes human needs, the Systems structure provides a synthesis of these approaches. The Systems structure is best characterized by its qualities of interrelatedness of its members, equifinality, homeostasis, and an information network system. Note that the terms equifinality and homeostasis are used here to mean that a problem can be addressed from different perspectives and that there is a tendency to maintain a relatively stable environment, respectively. The systems structure would then take up the position in the middle, and is in part attributable to the decision making models of March and Simon (1958), and Cyert and March (1963). According to Goldhaber, each of these organizational structures not only provides a framework for defining operational practices and the "order of business", they determine the communication patterns, effectiveness, and climate. In addition, structure may influence employee satisfaction and the 
overall longevity of the organization.9 These organizational structures are listed according to how they employ a participative approach to management, moving from lesser to greater, respectively. This system of categorizing organizations provides a good way to look at organizational communication and participative management, as well as a method of applying decision making theory.

Theorists have approached decision making primarily from three different perspectives: mathematical modeling, paradigmatic models, and models for practical application. Mathematical models are designed for use in solving single or multi-attribute problems of a technical or economic nature. Representative of this type of model is the work of Horowitz whose decision making model for business focuses on the quantitative outcome rather than the process. 10 Horowitz applies mathematic microeconomic theory as a decision making tool to the organizational context. Due to its orientation to outcome, rather than process, the mathematic model was not considered for this study. Unlike the mathematical model, the paradigmatic model focuses almost exclusively on the process of decision making. The paradigm approach is best characterized by the work of Azumi

${ }^{9}$ Gerald M. Goldhaber, Organizational Communication, (Auburgue, Iowa: War. C. Brown Co., 1979), pp. 33-70.

${ }^{10}$ Ira Horowitz, Decision Making and the Theory of the Firm (N.Y.: Holt, Rinehart, and Winston, Inc., 1972). 
and Hage in which they identify sixteen decision making variables, each with its own process. 11 The paradigmatic approach has been applied to practical settings and found to be useful; however, because paradigm models do not allow one to look at outcome or qualify the effectiveness of the process, these models were not employed in this study. Lastly, those models for practical application synthesize the outcome feature of mathematical models and the process attribute of pardigm models. Theorists of decision making models for practical application have taken two main approaches, power and participation, which will be central to this study.

Two ways of understanding decision making in an organizational context are to categorize the methods according to the authority approach or type of power utilized and the frequency of participation. Greiner has identified a Power Distribution Continuum in which he applies corresponding decision approaches. His continuum is designed with three types of power: unilateral, shared, and delegated. To these three types of power he assigns the appropriate decision making technique: decree, replacement, structural; group decision, group problem solving; and, data

$11_{\text {Koya Azumi and Jerald Hage, Organizational Systems }}$ (Lexington, Mass.: D.C. Heath, 1972), $\frac{\mathrm{Ch} 7 .}{6}$ 
collection, sensitivity training, respectively. 12 similarly, Pace and Boren have described decision making strategies on the basis of power distribution, wherein they are identified as: decision through power, decision through vocal coalition, decision through majority vote, decision through plurality, decision through consensus, and decision through unanimity. 13 Connor provides yet a third approach to understanding organizational decision making. He describes the four most commonly used strategies as: computation, judgment, compromise, and inspiration. 14 The common theme in all of these approaches to defining and describing decision making theory is that there is progressively increasing member participation.

Participation is clearly an important factor in describing and categorizing decision making methods. An understanding of the usefulness of participation in decision making is significant when selecting a model for application. According to work done by Heller on participative decision making, a nonparticipative approach

12L. E. Greiner, "Patterns of Organizational Change," Harvard Business Review, Vol. 45, No . 3, (1967): 119-130.

13 Common decision making strategies as outlined by $\mathrm{R}$. W. Pace and R. Boren, The Human Transaction (Glenview, Il1.: Scott Foresman, 1973).

14 Patrick E. Connor, Organizations: Theory and Design (CA: Science Research Associates, Inc., 1980). 
will likely be employed if a decision is important for the entire organization; if the decision affects the subordinates' work, a more participative approach will be used; and, if the decision makers perceive that the subordinates might contribute to the decision or its implementation, they will most likely employ a participative style. This is done on the basis of bounded rationality, i.e., those choices which are strategic are not necessarily the most optimal choices, rather they appear optimal because of the political process of the organization. 15 Note also that participative decision making is considerably more time consuming than an autocratic approach. The significance of knowing when to employ and when not to employ a participative approach is of even greater importance during periods of change or crisis.

As noted in the Introduction, when crisis or change occurs there is an alteration in the dynamics of the decision making process (March, 1979). March states that one or more of the decision making factors may be altered as a result of crisis, e.g., the distribution of power or the level of participation, even the communication environment itself.

15Frank A. Heller, "Leadership Decision Making and Contingency Theory," Industrial Relations, Vol. 12, No.2, ( May 1973), pp. 183-199. 
The Classical view, as represented by Argyris, suggests that crisis causes a shift in decision-making practices such that they become more autocratic in the sense that decisions-making resides more completely in the hands of the person with the most power. Argyris goes on to say that this shift to more autocratic style is characterized by a lack of individual conformity to the expectations of a normally operating hierarchy, where more attempt to direct would be expected from a broader range of participants. 16 This deviance from group norm manifest in a lower than normal amount of conflict during crisis situations.

In contrast to the Classical view, the Human Relations view as depicted by Rosenfeld predicts an increase in member participation during crisis. 17 This increased participation is accompanied by an increase in group conformity to norms and expectations of high interaction and consequently, conflict increases above normal levels.

Regardless of the presence of crisis or not, organizations exhibit varying degrees of uncertainty or ambiguity. According to Duncan, organizations "with dynamic environments always experience significantly more

16 Chris Argyris, Interpersonal Competence and Organizational Effectiveness (Homewood, Ill: The Dorsey Press Inc., 1962), pp. 57-73.

${ }^{17}$ L. B. Rosenfeld, Human Interaction in the Small Group Setting (Columbus, ohio: C. Merrill, 1973). 
uncertainty in decision making regardless of whether their environment is simple or complex."18 There can be no doubt that a large metropolitan hospital is such a dynamic environment and this study will examine these issues as they related to such an environment.

Decision making models in and of health care, physicians, and hospitals are innumerable. Krischner (1980) has comprised an annotated bibliography of 110 decision making applications attentive to health care. Krischner categorizes these applications into five groups: Probability Assessment/Analysis, Single Attribute, Multiattribute, Group, and General Discussion/Collaborative applications. These methods are defined below. Probability Assessment is the objective assessment of known information in which a decision is made based on probability. Single Attribute decision making is the choosing from among a set of alternatives that are described in terms of single attributes. Likewise, Multiattribute decision alternatives are described in terms of multiple attributes. Group decision making is the choosing from alternatives based on the judgment of a select few. Decision making by General Discussion is the choosing from

$18_{\text {R. B. Duncan, "Characteristics of Organizational }}$ Environment and Perceived Environmental Uncertainty," Administrative Science Quarterly, 17 (1972) pp. 313-327. 


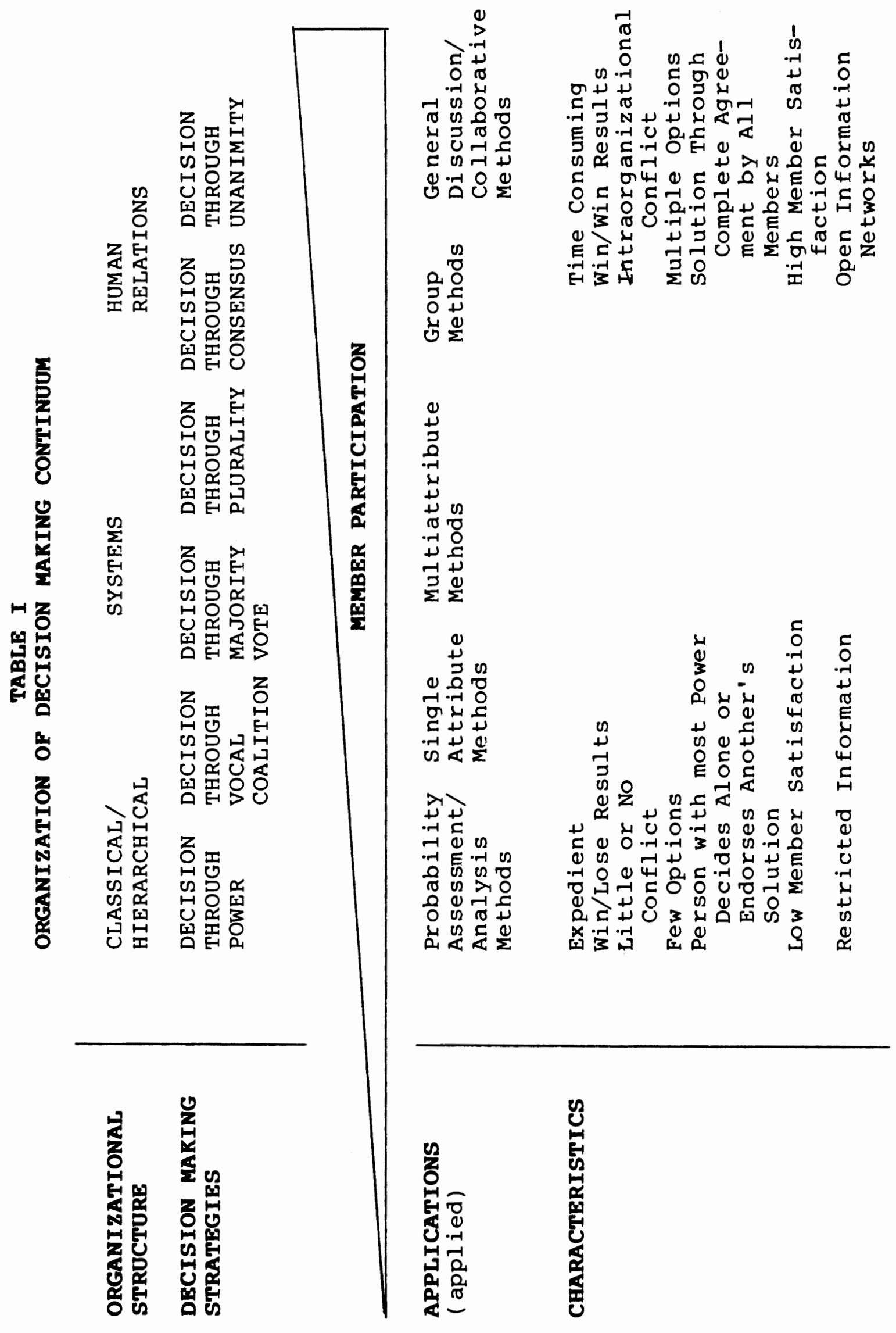


alternatives based on the judgment and mutual interaction of all those interested in or affected by the outcome. These methods also move from a lesser to a greater participative approach. Table I is a summary of organizational theory, organizational decision making. It depicts Krischner's Decision Analytic Applications, and provides a composite of the characteristics of the applications as they exist on a participative continuum. It is this table of Decision Making Methods to which I will refer throughout this paper. The research questions 1 isted in the Introduction will be pursued within the guidelines of Anderson's definition of decision making (C.F. page 5).

While this study will use this continuum to apply the characteristics of decision making, there are other interactive factors which influence this process. These factors will not be addressed specifically because they are beyond the scope of this study. These factors affecting organizational decision making embrace individual power, tradition and precedent of the organization, the organization's relationship with its environment, and financial resources to name a few. 19

Just as Krischner has applied decision theory to health care, Gordon has applied interviewing techniques to

19Richard H. Hall, Organizations' Structure and process (N.J.: Prentice-Hall, Inc., 1982), pp. 38-69. 
health care and professional settings. Key techniques identified by Gordon for interviewing in the professional setting are as follows. One, the context should communicate the question and be motivating, i.e., focus on the issue. Two, questions should be specific and address the interviewers objective. Three, appropriate vocabulary and scope should be used in each interview. Finally, each interviewee should be assessed, i.e., friendly versus hostile, high status or low status, etc.

This study will elaborate on the application of decision making theory based on a continuum, ranging from a high to low degree of organizational structure. Corresponding to this decrease in organizational structure is a parallel rise in the frequency of employee participation. It is the intent of this study to identify the decision making characteristics of a dialysis program, as listed on the continuum, and look for changes as a result of the crisis. Due to the scope and definition of the crisis, and the great variety of decision making techniques and models available, it was necessary to restrict this study to those applications which apply, "in the context of prescriptive decision making in an uncertain environment

20 Jeffrey Krishner, "An Annotated Bibliography of Decision Analytic Applications to Health Care." Operations Research Vol. 28, No. 1, January-February 1980, pp. 97-113. 
using judgmental or empirically derived probabilities and/or subjectively assessed utility functions."20 Decision making "is defined in the study as: the act of selecting and committing one self or a group to a course of action."21 (C.F. review of literature.) Decision making applications which meet these critera may be divided into the following categories: Probability Assessment/Analysis, Single Attribute Methods, Multiattribute Methods, Group Method, and General Discussion/Collaborative Methods. 22 (C.F. review of literature.) These applications may be defined by their position on a continuum of organizational structure (Classical, Systems, Human Relations) as moving from a lesser to a greater participative approach to decision making, respectively. Refer to Table I for a description of this continuum, the applied applications, and their characteristics. Note that the term collaborative is used in this study to refer to those methods of decision making which are consensus oriented, i.e., maximum effort is directed toward cooperation among members, group efforts focus on win/win solutions, and outside assistance is commonly employed, e.g., consultants, to maximize effectiveness. The result of

22 Adapted from an outline provided by Krischner, Ibid. 21 The interpretation of decision making is abstracted from Barry Anderson, et. al., Concepts in Judgment and Decision Research, (N.Y.: Praeger Publishers, 1982). 
a collaborative method is generally better than the sum of the members participating in the process.

In summary the aim of this study is to analyze a dialysis program's decision making practices, during the Medicare crisis period, and apply the findings to the Decision Making Continuum through descriptive analysis. By utilizing this continuum, a determination of the approach to decision making employed prior to and following the Medicare crisis can be made, i.e., the decision making process. It also allows for measurement of the affects of the crisis on decision making, as well as its affects on the program being studied, i.e., did a change of decision making practices produce better outcomes as perceived by the decision makers. The following chapter will discuss the setting to which the Decision Making Continuum will be applied. In addition, it will describe the methods used to apply the aforementioned theory, i.e., through a Decision Making Survey and follow-up interview. 


\section{CHAPTER III METHODS}

A purpose for any case study is achieved by adapting methods to the particular setting under study. Having discussed the purpose in Chapter I, this chapter will provide the details of the setting most relevant to the determination of the method. The methods of assessing the decision making practices of the program will also be discussed; as they were addressed through the use of a Decision Making Survey and follow-up Interview, respectively. This chapter will conclude with a discussion of the limitations of this study.

The Good Samaritan Dialysis Program

Good Samaritan is a 539-bed acute care, speciality hospital and medical center serving the Portland tri-county area and southwest Washington. Good Samaritan is designated as a regional medical center and noted for programs such as the Rehabilitation Institute of Oregon, a Neurological Sciences Center, Devers Eye $\mathrm{Cl}$ inic, and the Oregon Lions Eye Bank. In addition, the hospital has gained national recognition for its well-developed programs in kidney dialysis and diabetes management, as well as Day, Primary, and Evening care services. 
The Dialysis Department is a 260 patient program specializing in home training and support for hemodialysis and peritoneal dialysis, acute care, and outpatient hemodialysis services. The program is divided into various units which include: an Inpatient Acute Unit, a Home Training and Support Unit, and various Outpatient Units. Structured in the classical organizational framework as seen in the Hospital's Formal Organizational Chart (Table 2), the hierarchy is as follows (note that only those positions in the hospital/program hierarchy pertinent to this study are listed): Second to the Chief Executive officer (C.E.O.) and Senior Vice-President of the hospital, is the Vice-President of Medical Services and Material Support whose responsibilites include the Dialysis Program. The administration of the program is the responsibility of the Dialysis Program Administrator, who shares joint responsibility with the Medical Director and the Assistant Medical Director. The Business, office, and various Unit Managers all answer to the Program Administrator. The Program Administrator, Medical Director, Assistant Medical Director, and the various managers comprise the Dialysis Management Council Group whose function is to act as a problem solving, decision making body. The final decision regarding any issue addressed by the Council is up to the Program Administrator. In addition, the program contains 
TABLE II

\section{FORMAL ORGANIzATIONAL CHART OF THE GOOD SAMARITAN BOSPITAL AND MEDICAL CBNTER DIALYSIS PROGRAM*}

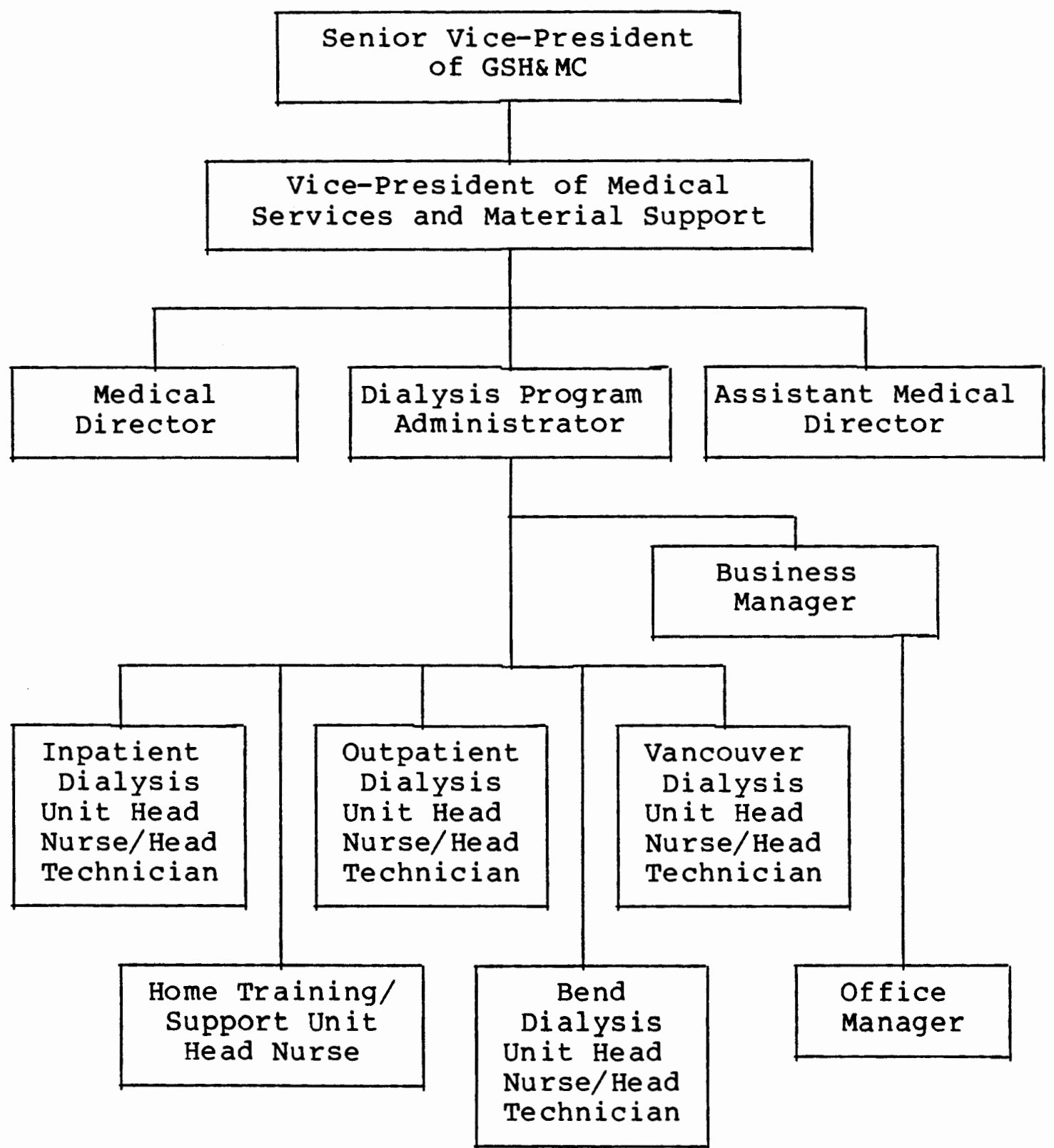

*Only positions pertinent to this study are shown. 
approximately 100 other part and full time staff members which include: Nurses, Technicians, Social Workers, Dietitians, Education and Financial Planners, and Secretaries. Although these people are not a part of the Dialysis Management Council, they are called upon from time to time to assist in addressing a problem as "experts" in a certain field. It is this group of employees which make up the Dialysis Department of the (GSH) Hospital and are responsible for its operation. The critera used to determine who was to be a subject of this study is as follows: First, they must be active members in the Dialysis Management Council or have been influential in providing direction or leadership for the council. Second, in addition to having been either a part of the decision making process or have affected the outcome of the major decisions, another criterion is that all subjects must have been associated with the dialysis program over the crisis period. The crisis period will be defined for purposes of this study as the period from May 1983, the time when Medicare law changes were initially published, to January 1984, six months following the effective date of the Medicare Law changes. Lastly, they must still be active in the dialysis program or available to discuss the activities of the crisis period. The subjects of this study include the members of the Dialysis Management Council, i.e., the Program 
Administrator, Medical Director and Assistant Medical Director, Business Manager, various Head Nurses and Head Technicians, and the office Manager, who is active secretary for the Council. This study will also include the VicePresident of Medical Services and Materials Support as he is influential in the decisions of the program. It was considered that, if through the course of the study others appeared to be significant in the program's decision making practices, they too would be included in the study. It was determined however that there were no additional subjects who met the criteria. The Head Nurse and Head Technician of the Bend Satellite Unit will not be included because they were not active participants in the Dialysis Council and its decisions. The Head Nurse of the Vancouver Outpatient Unit will not be included due to her lack of involvement with the Dialysis Department during the crisis period. (See Table 2).

\section{Methods}

The methods used to collect data for this study were through the use of a survey (Appendix A) and a follow-up interview. The survey was used in order to determine the method of decision making employed three months prior to and six months following the effective date for the Medicare changes, as characterized on the Decision Making Continuum (Table I). The survey was also used to determine the 
effects of the crisis on the dynamics or characteristics of decision making by addressing the research questions. The interview was used to check both the reliability and the validity of the survey data (C.F. Chapter IV on reliability and validity). In addition, the interview also served to determine the perceived affect of the crisis on decision making and patient care.

\section{The Decision Making Survey}

The Decision Making Survey was given to those people who met the criteria of decision makers in the dialysis program during the crisis period, as discussed above. The subjects included two administrators, two physicians, and eight of eleven managers. Those managers who were omitted did not meet the criteria.

The survey was divided into two sets of questions, each of which correlated with a respective time period. The first time period was from May, 1983 through August 1, 1983, from the time when Medicare law changes were first published and to when they became effective. The second time period was from August 1, 1983 through January 1984, allowing a six month transition period following the implementation of Medicare changes. These two periods of time will be referred to as Period One and Period Two, respectively. 
So that the systematic error of recall might be reduced, i.e., subjects were not asked to recall past events, the body of the survey was composed by referring to the past minutes of the meetings of the Dialysis Council. The minutes from the meetings of May 1983 through those of January 1984 were reviewed. Any issue which was listed in the minutes as a problem which the group acknowledged, discussed, and acted upon was identified as a problem/ decision. Frequently, a problem/decision would be recurrent at many meetings, and thus would only be listed once in the survey. Listed in the survey are major issues identified as problems/decisions for each of the two periods.

As seen by the survey, subjects were asked a similar set of questions for each period. As identified by the Meeting Minutes of the Dialysis Management Council Group, subjects were asked to rank the decisions of a given period, from their point of view, in order of their importance. Decisions/Problems were identified from the Meeting Minutes of the Dialysis Management Council Group and listed in random order. It should be mentioned that the decisions/problems identified in the Decision Making Survey as seen in Appendix $A$ have been generalized or slightly altered from the survey given to the subjects to avoid divulging specifics of this program's operations. The ranking was followed by a series of 15 questions addressing 
the single decision that the subject identified as the most important. The purpose of these questions was to collect data that would describe and identify a specific method or pattern in decision making as exhibited on the Decision Making continuum. The aim of the following questions is to address the characteristics of decision making as perceived by the subjects.

1) How were the decisions ranked in terms of their severity and immediacy as perceived by the subject for each of the two periods?

The purpose of this question is to address the participant's perception of the crisis as it relates to decision making. This question seeks to determine if there was greater consensus among the subjects as to the importance, i.e., severity and immediacy, of the decisions of one period over another. Should one period exhibit greater consensus than another it will help in part to address the earlier question of whether crisis produces greater or less conformity among group members as discussed by Rosenfeld and Argyris (C.F. Chapter II).

2) Which member(s) most often phrased the solution to crisis problems for each Period, i.e., Period one and Two?

This question is addressing the issue of power as employed in decision making strategies. The literature shows that a 
characterization of decision making may be made on the basis of the type of power employed. (C.F. Chapter II for Greiner, and Pace and Boren's work on decision making through power.)

3) What is the estimated amount of time associated with the primary decisions of each Period? This question addresses the efficiency of the decision making technique(s) employed, e.g., a more participative approach will take longer. (C.F. p. 15 for Heller's work on participative decision making.)

4) Which period was perceived to have a greater amount of conflict associated with the discovery of a solution?

This question not only allows for the determination of the amount of conflict for each period, it also helps to determine the participant's perception of the value of conflict in the decision process. According to the literature more conflict with perceived greater value should result if decision making becomes more participative, or less conflict with lower perceived value should it become more autocratic. (C.F. Argyris and Rosenfeld p. 16.)

5) During which period did the subject's feel better about the final decision and their input into that decision?

This question addresses the role of member satisfaction in 
the decision making process, e.g., members should express greater satisfaction with a participative approach.(C.F. Chapter II, and Katz and Kahn's work on organizational psychology.)

6) What is the subjects overall interpretation of decision options and channels of communication, i.e., satisfaction with method for each period? This question addresses the issues of decision making structure, information pathways, and member satisfaction. According to the literature the more autocratic the decision making the more hierarchical the decision making structure. As the decision making structure solidifies, i.e., becomes increasingly more hierarchical, both the flow of information and member satisfaction drop off. (C.F. Chapter II on organizational structure and decision making.)

7) Was there an identifiable breakdown of the formal (hierarchical) organizational structure, and any alternative if such a breakdown is identified? That is, was there an alteration in the decision making practices of the program, i.e., did the process become more or less participative, as a result of the crisis. As noted in the literature there should be a shift toward one direction or another. (C.F. Chapter II Argyris and Rosenfeld .)

8) What decision making methods (applications) were 
used during each period, i.e., was there a change in method?

The decision making method may be determined by its character properties, e.g., power, participation, etc. (C.F. Greiner, Pace and Boren, and Connor's, Chapter II.)

9) Which primary decision applications employed relative to their overall efficiency, conflict and member satisfaction was most effective?

Which decision making method, (providing there was a change of method), was perceived to be the most effective.

\section{Decision Making Interview}

Interviews with the subjects were conducted over a two to three week period following the collection of the Decision Making Survey. These interviews were conducted using the methods described by Gordon (1980), in his work on interviewing in the professional setting. This method was adopted for the interview as described in Chapter II (C.F. review of literature) wherein, the interviews were conceptually organized in four steps. First, the conversation was focused on the issue, i.e., decision making and the Medicare crisis. Second, each question was phrased so that it addressed specific objectives. Third, the appropriate vocabulary, scope, and intensity was expressed. And last, each subject was evaluated to determine the overall tactic needed, i.e., is the subject friendly or 
hostile, of high or low status, a key informant or a representative, etc. 23 Appendix $B$ contains a list of the topic questions addressed during each interview. Note that questions initially addressed a narrow scope of the problem and became more broad in the course of the interview. It was the intention of these interviews to promote spontaneous responses toward the following objectives.

1) To discover the subject's attitude toward the study and the interviews, in that a poor attitude may reduce the validity of the subject's responses.

2) To look for discrepancies between survey and interview responses, and between subjects, as a second check on the validity of the subject's responses.

3) To detail the subject's interpretation of decision options and channels of communication.

4) Should a breakdown of the formal communication system be indicated by the survey response, to identify the dynamics of such a breakdown.

5) To discover if the subject's perceived that decisions made as a result of, and during the Medicare crisis have had an impact on the overall

23Raymond L. Gordon, Interviewing: Strategies, Techniques, and Tactics (Homewood, Ill.: The Dorsey Press, 1980), pp. 125-145, 275-313, 411-441. 
quality of patient care.

The purpose of the interview sessions was to validate the information provided in the survey, determine the reliability of the survey information and obtain descriptive information on the decision making process of the Dialysis Department.24 A secondary function of the interviews was to provide supportive information for the determination of the affects of the crisis, if any, on the decision making process. The interview method was chosen for follow-up data collection in the hopes that personal interaction would provide more, more accurate, and descriptive information of the decision making processes and the respective climate, i.e., for Periods I and II. All interviews were conducted by the author. Most of the interview questions were simply a restating of the questions from the Decision Making Survey. Those interview questions which did not appear on the questionnaire were related to secondary issues of this study, e.g., the impact of the crisis on the quality of patient care or the subject's perception of what could be done to improve the program's decision making practices.

24 Note that both the terms validity and reliability are used here in there simpliest definition and are not meant to imply statistical inference. When statistics are used in this study they are intended to be purely descriptive and in no way quantify the decision making process. 


\section{Limitations of the Study}

The design and focus of this study have resulted in various limitations. This section will discuss the following limitations: the need for the subjects to remain amonymous; the reliability of the method and the data, as well as its validity; and the "narrowness" of the scope of this study.

In gathering data for this study participants were assured that their names and the information they disclosed would remain anonymous. To secure subject anonymity it was necessary to generalize both the survey and interview responses according to either a category based on hierarchy or one based on function. The hierarchy of the subjects is generalized as follows: the Vice-President of Medical Services and Material Support, the Dialysis Program Administrator, the Medical Director and Assistant Medical Director of the Dialysis Program will all be referred to as Administration; the Business and office Managers will be referred to as Middle Management; and the Head Nurses and Head Technicians will constitute Management. Some of the research questions will be addressed using this categorization, while other questions mandate another grouping. Some questions will require a division of the subjects on the basis of their administrative or medical function. The administrative and medical personnel are 
categorized such that the Medical Director, the Assistant Medical Director, Nurses, and Technicians constitute the Medical Personnel, while the remainder comprise the Adninistrative Personnel. These two categories will be used throughout the remainder of this paper to discuss the decision making process. The function of these categories is to compensate for the limitations of the subject anonymity, so that hierarchy and function trends in the decision process may be discussed.

The reliability of the methods used is yet another limitation of this study for two reasons. One, this is not an empirical study and therefore reliability cannot be measured. Second, as this is a case study of only one program's response to the Medicare crisis, these methods have yet to be applied to other programs or situations. Reliability can however be determined by an analysis of the data. Reliability may be determined by a subjective comparison of each subject's survey and interview response. Recall that many of the interview questions were rephrased survey questions. (C.F. Chapter IV for a discussion of the comparison between survey and interview responses. ) This method may be considered a type of alternative forms reliability, and thereby reduces the reliability limitation of this study.

Like reliability, there are two issues of validity to 
be addressed, concurrent and construct. The test of concurrence validity is employed here as a comparison of the data from the structured survey with the relatively unstructured interview. (C.F. Chapter IV for a discussion of the comparison of the survey and interview. ) Again, like reliability, validity is viewed as a potential study limitation because of the absence of quantification. The final limitation recognized is the narrow scope of this study. Because this study examines only one organization, with methods that are as yet untested, it cannot be stated with certainty that this study is applicable to other organizations or situations. Further, this study has been limited by its focus on the affects of the crisis on the decision making process. It was assumed by the author that there were no other major influences on this process, other than the crisis itself. However, other external factors like the regional economic conditions or politics, in addition to those discussed in the preceeding chapter, may have also had an impact on the process. The exclusion of these factors has allowed for a concise analysis of a dialysis program and the affects of the 1983 Medicare changes on decision making practices; although, it may have limited its application to other programs.

In the following chapter the information gathered from the survey and interview is analyzed. These data are 
primarily applied to defining the characteristics of the decision process and addressing the research questions of this study. 
CHAPTER IV

DATA ANALYSIS AND RESULTS

This chapter will systematically address the research questions posed in Chapters I and III. Specifically, this chapter will descriptively analyze the data concerning reliability and validity; the affects of the crisis on perception, power, efficiency, conflict, member satisfaction, and overall decision making methods employed; and, the participant's perception of decision making options and the affects of the crisis on patient care.

In addressing the research question of discrepancies between a subject's survey and interview responses the following was revealed. Of the twelve participants given surveys and interviewed, there were three discrepancies that were discernable. There was one discrepancy from each of the three organizational groups, i.e., Administration, Middle Management, and Management; therefore, the discrepancies were not position related. The observed discrepancies were as follows. The Administration discrepancy focused on the issue of conflict during Period I and Period II. Middle Management and Management groups both had observed discrepancies on an issue of the efficiency of the decision making process during the two periods. It is my opinion that the Administration discrepancy was due to 
the "depth of scope" taken during the interview that was not defined in the survey, i.e., conflict as it was perceived to affect the decisions of the Dialysis Program and not just the roles of the individual. It is less clear what the cause of the other two discrepancies was due to, although they too may have been the result of the "depth of scope" taken during the interview that was not evident in the survey. It may be said that given so few discrepancies between survey and interview data that the method used was both reliable and valid.

In addressing the questions of the subjects' attitudes towards the study, the survey, and the interview, the following was revealed. Analysis of the interview responses revealed that with the exception of one of the Administration, all of the subjects were generally positive about the study and methods. Participants commonly expressed that they viewed the study as an opportunity to be introspective with regard to their decision making process. While the one Administration member did not express enthusiasm about the study, he was cooperative and responded to survey and interview items. It is believed that the openness of the participants in this study was reflective of their interest in making better and more timely decisions. Further, this openness has provided a far better insight into the decision making process of the Program that would not have been 
evident from the survey and interview question responses alone. The subjects' detailed description of the events during the crisis provides the information needed to characterize the decision application employed during each period. It may be said that the subject's attitudes toward the study in no way hindered the data received, rather it served to provide additional information.

The questions outlined in Chapter III address most of the characteristics of applications employed in organizational decision making. These characteristics or factors which describe the method of decision making include perception, power, conflict, efficiency, and desired outcome. Each of these characteristics will be analyzed and compared between periods and intersubjectively by answering the seven data questions outlined, followed by an analysis of secondary issues. Note that in most instances the power holders are the ones who shape and decide what are issues and nonissues. Because the characteristics of perception and power are so closely tied, these characteristics will be addressed first.

Question 1: How were the decisions ranked in terms of their severity and immediacy as perceived by the subject for each period? 
Subjects were asked to rank the decisions listed in the survey for each of the two periods. Recall that these decisions were identified from the minutes of the meetings of the participants'. These decisions are broken down by period and listed numerically in Appendix A. Figure 1 reveals that a consensus of the importance of the decisions during Period I is significantly less clear than for those decisions of period II. It is evident from the figure that there was a moderate to low level of consensus regarding the importance of issues during Period I. Conversely, during Period II there was clearly conformity regarding the importance of the adminstrative decisions resulting from Medicare, i.e., the interpretation of the Medicare changes and how to deal with them. While an array of issues of a medical and administrative nature were identified as the three most important for Period I, this was not true for Period II. These decisions identified as the three most important for Period II were almost exclusively of an administrative or program nature. Figure 2 provides a comparison of those decisions which were ranked as the most important for each period. This figure further delineates the types of decisions identified during each period. Of the decisions identified as the most important for Period I, thirty-three percent (decision \#13) were of an administrative nature, and sixty-seven percent (decisions 


\section{TABLE III \\ Decisions Made by the GSB Dialysis Progran During the Crisis Period}

Decisions/problems preceded by an (A) are designated Administrative decisions and those followed by an (M) are designated Medical decisions.

Period I: May 1983 through July 1983

1. A Communication problems regarding hospital admissions/ discharge procedures.

2. A Leasing/renovations of an outpatient facility.

3. M Change in peritoneal dialysis protocol.

4. A Change in billing method for home patients.

5. A Resolution of a clear financial statement.

6. A Long term facility planning.

7. A Changing protocol for patient travel.

8. M Change in protocol and responsibility for medications.

9. $M$ Dialyzer re-use project and protocol.

10. $M$ Transplantation transfusion protocol.

11. A Closure of Acute Unit night shift.

12. A Loss of patients to another facility.

13. A Hiring a consultant to help deal with the upcoming Medicare changes.

14. M Treatment of AIDS patients.

15. M Reorganization of dialysate delivery system.

16. M New Code System for Outpatient Unit.

Period II: August 1983 through January 1984

1. A Interpretation of the new Medicare changes, i.e., the Dialysis Reimbursement Schedule.

2. A Need and methods of improving efficiency and reducing personnel as a result of Medicare changes, i.e., change of staffing and scheduling.

3. M A backlog of peritoneal patients in the hospital.

4. M Problems associated with the dialyzer re-use program.

5. M Deletion of "special" dialysate baths from those offered as a time conservation measure.

6. A Responses and actions taken as a result of the 1982 Network Coordinating Council \#2 publication on ESRD.

7. M Resolution of defective water treatment units.

8. M Need for a new protocol for patients with confirmed non-A/non-B Hepatitis.

9. A Need for a new billing procedure as a result of the Medicare Dialysis Reimbursement schedule.

10. A OTHER as identified by subject 
Fiqure 1: Ranking of decisions from the Decision Making Survey.

\section{RANKING OF DECISIOAS FOR PERIOD I (hay 1983 through July 1983)}

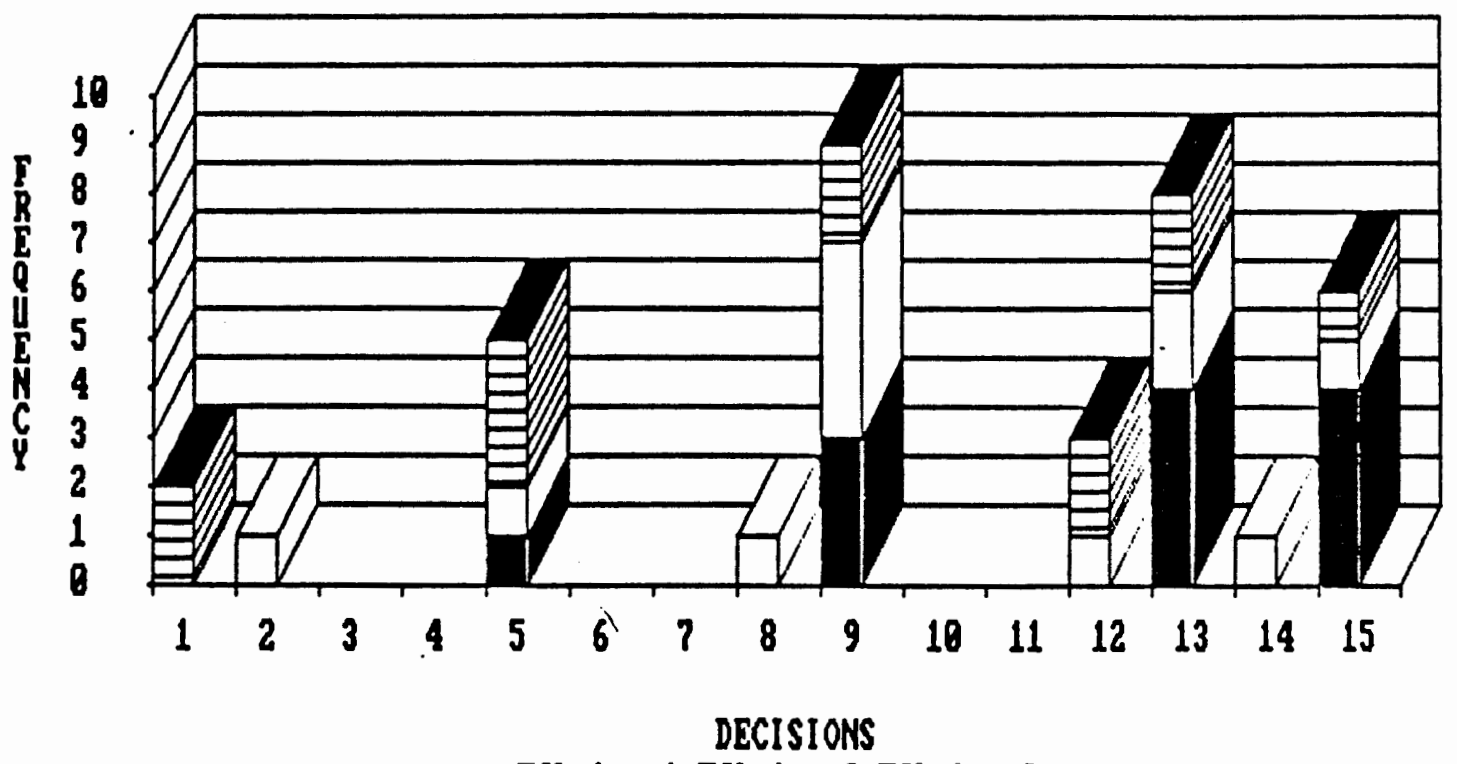

Choice 1 Choice 2 EChoice 3

RANKING OF DECISIONS TOR PERIOD II

(August 1983 through January 1984)

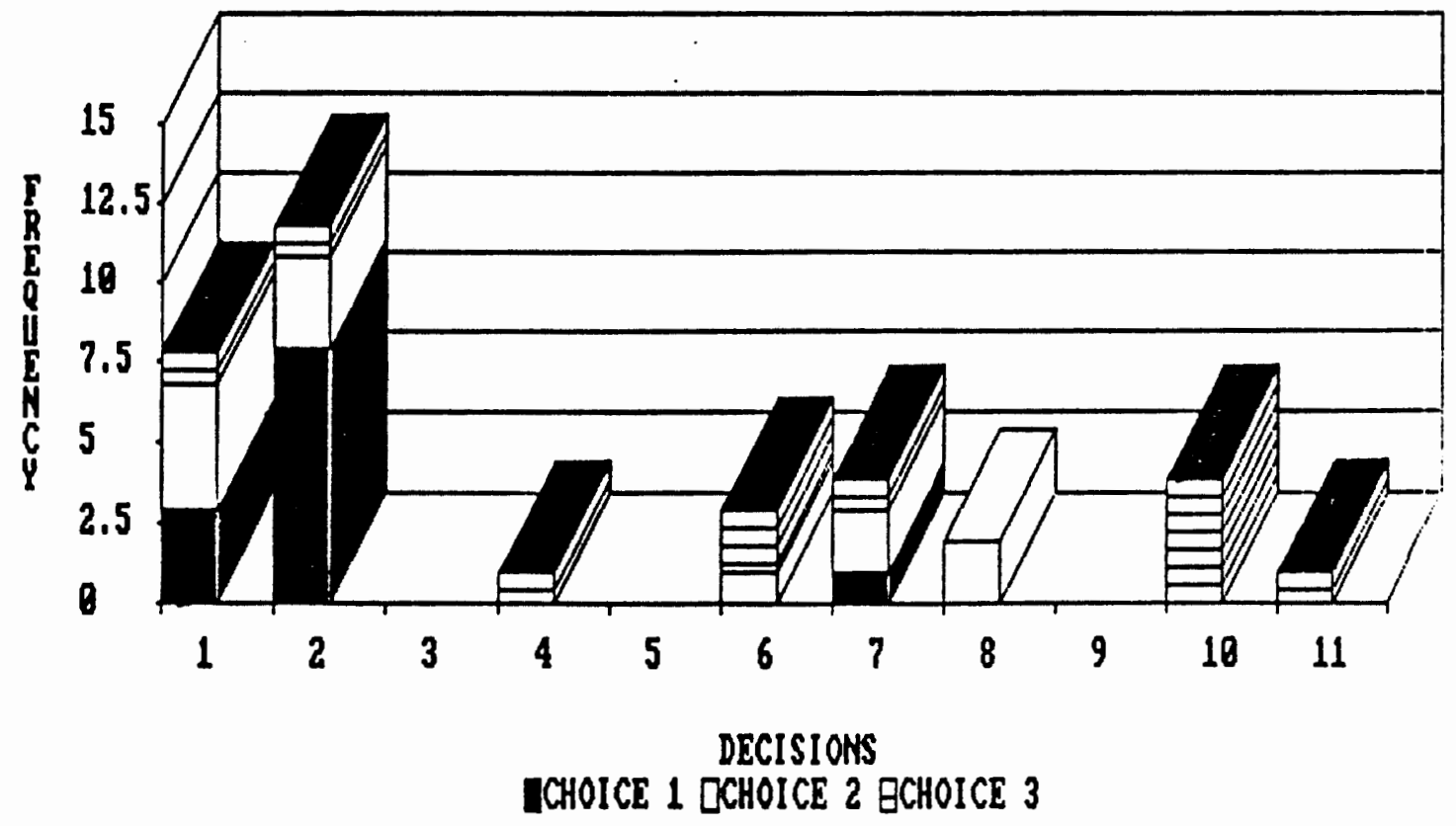


Figure 2: Decision ranked as most important from Decision Making Survey.

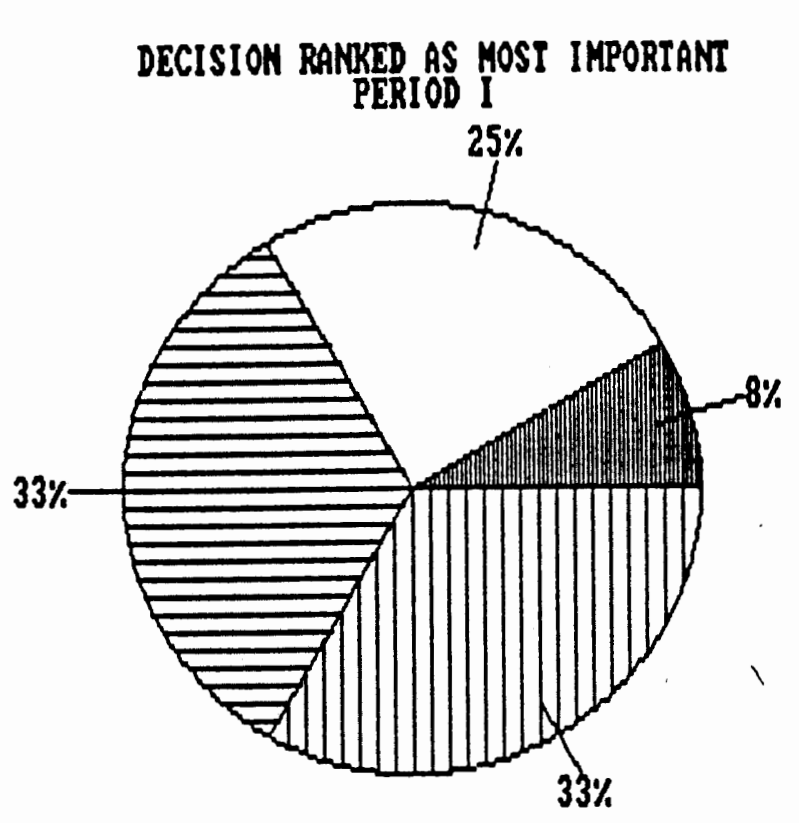

DECISION RANKED AS MOST IMPORTANT PERIOD II

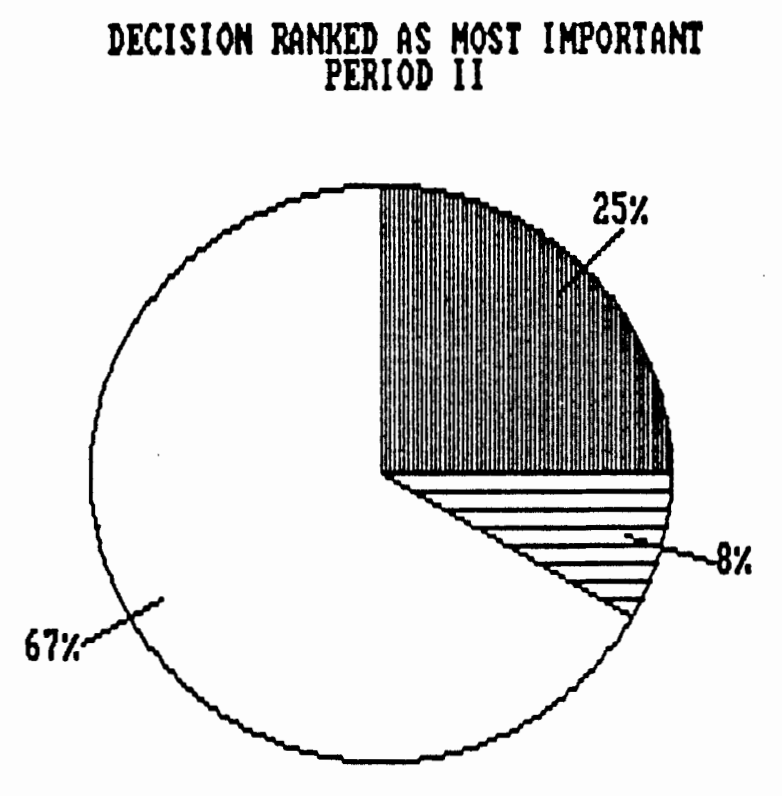

CHOICE 1

Decision 3

Decision 9

Decision 13

WD Decision 15

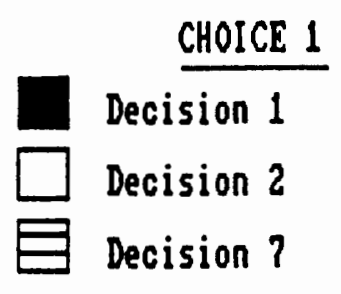


$\# 3$, \#9, and \#15) were of a medical nature. Primary decisions identified for Period II were comprised of ninety-two percent (decisions \#1 and \#2) administrative and eight percent medical (decision \#7). Clearly, there was greater consensus regarding Period II decisions. While the consensus regarding Period II decisions does not confirm the notion that crisis produces conformity, it does provide evidence in that direction. The remaining questions will also touch on the issue of conformity.

Question 2: Which members most often phrased the solution to crisis problems for each period, i.e., Period one and Two?

Subjects were asked to identify the person(s) whom they recalled first stating "the solution" to the problem/decision they had identified as most important. Again, it is necessary to address this question using the subject groups employed earlier. Analysis of the survey data revealed that for Period I all of the Administration thought they had stated the solution, i.e., four out of four Administration. One of the two Middle Management personnel thought an Administration person had stated the solution; while the other Middle Management person could not recall. Four of the six Managers recalled the solutions as being stated by Management. of the remaining two Managers, one 
thought the solution was stated by an Administrator, the other by a Middle Manager. It is apparent that Administration thought they solved the problems, and Management thought they did the solving, for Period I. However, like the answer to the preceding question of perception, this pattern was not the same for Period II. Eight of the twelve subjects responded that a member of Administration first stated the problem for Period II. Responses from the four remaining subjects was as follows: two subjects could not recall, one thought the solution was stated by Middle Management, and one thought the solution came from an outside source. Thus, the crisis moved the perception of power from each of the groups thinking it solved the problems, to most of the members (two-thirds) thinking Administration solved the problems.

Employing the Administration/Medical Personnel categories of the subjects, the above pattern was even more definitive. All of the Administration thought the solution to Period I problems had been stated by an Administrator. While half of the Medical personnel thought the solution had been stated by an Administrator, the other half thought it had been stated by a Medical peer. For Period II, all but one subject agreed that the solutions had been stated by an administrator. The only exception was the subject who could not recall who stated the solution. To apply 
these findings to that portion of the Decision Making Continuum addressing power (C.F. Table I), it is clear that the crisis shifted the power for decision making from decision making through plurality to decision making through vocal coalition. That is, the power for making decisions shifted from all group members to a few administrators, which would support the Argyris' notion that decision making becomes more autocratic with less conformity. With reference to Table I, this shift represents a move from greater to lesser participation.

Question 3: What was the estimated amount of time associated with the primary decision for each Period?

In completing the survey, subjects were asked to estimate the amount of time spent to reach a solution to the problem they had identified as most important. Responses to this survey item were mixed and varied ranging from six hours to "little" for Period I, to twenty-six weeks or several months for Period II. Regardless of the grouping of the subjects, e.g., Administrative or Medical Personnel, the overall pattern was from a smaller to a large amount of time over the crisis period. Without exception subject responses indicated a move from lesser to a greater amount of time spent to reach decisions for Periods I and II respectively. Similarly, subjects were asked during the interview to 
recall during which Period the primary decision took the greatest amont of time to solve. Interview responses supported the pattern identified by the survey data, i.e., Period II decisions took significantly longer to solve. There was one subject who expressed that they thought Period II decisions were made more efficiently rather than vice versa. This exception to the pattern is probably due to the subject's perception of the most important problem for Period II. This subject was the nonconformist who thought a medical decision more important than an administrative decision for Period II. Thus, because the decision making group thought administrative problems were of primary importance for Period II, they spent far less time on medical problems. In summary, the survey and interview responses overwhelmingly demonstrated that period I decisions took less time, and thus the process used was more efficient.

Question 4: Which period was perceived to have a greater amount of conflict asociated with discovery of a solution?

Again, based on the decision identified by the subject as the most important for each period, subjects were asked to estimate the amount of conflict and if that conflict served a purpose. Analysis of the survey and interview data reveal that, regardless of the subject groupings, partici- 
pants' thought that there was significantly more conflict associated with reaching a solution during Period II than in Period I. Three of the twelve subjects thought that the frequency of conflict remained the same; whereas, the remainder of the subjects thought there had been a significant increase in the frequency of conflict during Period II. While it is clear that decision makers agreed that there was more conflict in Period II, this was not the case for its perceived usefulness.

Although it was unanimous that the frequency of conflict increased, the Administrative and Medical personnel disagreed on its usefullness. Overall, both groups expressed relative indifference regarding the decisions of period I, i.e. whether or not it was useful in making decisions. However, these two groups disagreed about the usefullness of conflict associated with Period II decisions. All four of the Administrative Personnel thought that although conflict had increased during period II, it was "good" because it forced better answers and new perspectives. The Medical personnel however did not all agree that the conflict was good. Three of the eight Medical personnel thought that the Period II conflict was useful, one subject was indifferent, and the remaining four subjects thought the conflict was "bad" or detrimental to the decision making process of the group. Analysis of the interview responses reveal that 
Administrative Personnel most commonly perceived the conflict of Period II as a result of conflicts of role and interest. In contrast, the Medical personnel typically expressed that values and special interests were the causes of the conflict. The fact that conflict occurred would, if interpreted in terms of the model in Table $I$, indicate an increase in member participation.

Question 5: In which Period did the subjects "feel better" about the final decision and their input into that decision?

Subjects were asked in the survey if they felt their view was included in the final solution and how they felt about the solution to the problem they had identified as most important. Further, would they have liked to have had, or should they have had more, the same, or less input into the process. These questions were asked for each Period in the questionnaire and reworded for the Interview. An analysis of the responses reveals mixed answers to these questions.

Using the Administration/Medical Personnel grouping, the survey response to the above questions is as follows. Two of the four Administrative Personnel felt better about the Period II decision and that the need and application of their input was appropriate. One subject felt better about 
the Period I decision, but that more of their input was used and needed during Period II. The final Administrative subject felt the two periods were equal in terms of satisfaction with the process and the amount and necessity of their input. Likewise, two of the Medical personnel expressed an increase of satisfaction with the Period II decisions, four expressed a decrease in satisfaction, and two felt the Periods were equally satisfying. All of the Medical Personnel responses indicated that they thought they had had the appropriate amount of input. These results are inconclusive, and thus it cannot be said from the survey responses that the process used during one period was more satisfying than another. However, the interview data revealed that members perceived greater satisfaction with the decision making process of the second period.

Subjects were asked during the interview to identify which period they and their peers felt better about the decision reached. Three of the four Administrative Personnel thought that they and their peers were more satisfied with the decisions of the second period, and the fourth person thought both periods were equally satisfying. The Medical personnel also thought Period II decision making was more satisfying. Six of the eight Medical personnel expressed a preference in satisfaction with the Period II process, while only two expressed a preference for Period I. 
Clearly the Administrative and Medical personnel equally agreed that period II was more satisfying. Recall that the survey and interview questions were not the same, i.e., the survey question focused on the decision identified by the subject as most important and the interview question focused on satisfaction with the overall process of each period. Thus, it may be said that the overall process employed during Period II was more satisfying than the one used during Period I, although perhaps not for the most important decision of each period. The fact that overall satisfaction increased would, if interpreted in terms of Table $I$, indicate an increase in member participation and a shift of the corresponding characteristics.

Question 6: What were the subjects' overall interpretation of decision options, channels of communication, and the availability of information.

This question will be addressed by answering three underlying questions. One, were the decisions of each period reached using a formal or an informal method. Second, did the subjects think that they had access to the information they needed to contribute to the decision. Third, did the subject's perceive that the communication channels were open to them.

For those decisions ranked as most important for 
Period I, ten of the twelve subjects thought the decision was reached formally. Those two subjects who thought the most important decisions for Period I was reached informally were in the Administration and Management group respective1y. Similarly, Period II decisions also were thought to have been decided formally. One subject from each of the three hierarchical groupings thought period II decisions were made informally. The remaining nine thought period II decisions were made formally. The overall consensus then is that regardless of period or position decisions were thought to have been reached using formal procedures.

This pattern of using a formalized protocol for decision making may in part be due to the availability of information. Upon analysis, it was found that regardless of subject group designation "most" of the information needed to contribute to the decision process of Period I was available. During Period II however it was thought that there was a slight increase in the availability of information, e.g., generally "all" of the needed information was available. It was the Medical Personnel who thought that an increase in information availability took place. Thus, the decision making procedure used during Period II offered slightly more information as perceived by its participants. Lastly, having addressed the formality of the procedure used and the availability of the information 
offered, the next step is to discuss the availability of communication channels and processes. Upon analysis it was observed that regardless of subject group designation for Period I, half of the participants thought the channels of communication were open to them while the other half did not think it was available. During Period II however, all of the Administration thought the communication channels were open to them. Conversely, both of the Middle Management thought the doors were closed to them. Like the Middle Management, five of the six Management thought the communication channels were closed to them. Clearly, those at the top of the hierarchy achieved greater information availability and utilized the information and the channels of the department. In summary, the decision making process became more formal, access to the channels of communication decreased, while the availability of information at all levels increased. If interpreted in terms of the model in Table I, the formalization of the process and the decrease in access to channels, would indicate a decrease in member participation; however, the increase in information availability indicates an increase in member participation.

Question 7: Did the decision making process employed during Period I become more or less participative during Period II?

Question \#8 regarding what decision making methods 
were used and Question \#9 regarding the overall effectiveness of the decision making applications that were employed, will be addressed in the following discussion. Based on the decision that was identified as the most important for each Period, subjects were asked to estimate how many people were involved in reaching a solution. Analysis of the data revealed that regardless of subject groupings, the subjects' thought that Period I decisions were made by a small select group. Unlike Period I, subjects throught that Period II decisions were made by either the entire department or the entire organization, including outside consultants. Obviously, the decision making process employed during period II was perceived to be far more participative in nature, in that more information was apparently available to those at the bottom of the hierarchy, than the one employed during period I.

As determined by the response to the preceding questions, the decision making method employed during Period I may be characterized as follows. Power for decision making was in the hands of the Administrative personnel. Decisions were made in a fairly expedient manner and were associated with a moderate amount of conflict. Member satisfaction with the decision making process may be characterized as low to moderate. Only a partial amount of information was available to the decision makers. 
Similarly, access to the channels of communciation was limited. Most important, decisions were made by only a few people, thus offering limited options for others.

Period II on the other hand may be characterized as follows. Here too, power for decision making remained in the hands of the Administrative personnel. Decisions were thought to take an extremely long time and were associated with a high level of constructive conflict. Although there was frequent conflict, member satisfaction with the process may be characterized as high. Further, the availability of information was thought to increase, while the channels of communciation remained the same, moderately open. Last and most important, decisions were thought to have been made and/or influenced by at least the entire department as well as outside consultants.

While the decision making practices were perceived by the subjects' to become more participative in nature, this may not have actually been the case. The preceding comparison between periods I and II points out that the crisis did not effect the hierarchy of the program, i.e., power remained in the hands of the administration; rather, the crisis may have served to further strengthen the hierarchy. While there was a perceived increase in information availability and participation as discussed in the preceding questions, subjects' also perceived a closing 
of the channels of communication, thus cementing the hierarchy. In answer to the question, then, as to whether or not participation increases during periods of crisis, it must be said that for this study, participation defined as access to channels decreased, while availability of information increased. In terms of member perception, participation increased. It might be concluded, then, that availability or openess of information is more important for perception of participation than access to the hierarchy where the decisions were in fact made.

Although it is not clear which specific decision making application was employed during each of the two periods, it is clear from the above comparison of Period I and Period II that there was a perceived shift towards a more participative approach to decision making. This shift towards a participative decision making method was done without shifting power to those in lower positions on the hierarchy. It may be concluded that the crisis did produce greater conformity among the decision makers, thus supporting Rosenfeld's thesis that crisis does produce conformity. The simultaneous shift to a participative style and the resulting conformity allowed for institutional changes to be put into effect by creating what was perceived to be an open supportive climate.

During the interview, subjects were asked what could 
be done to improve the decision making processes of the department. The most common response was that there should be better meeting management, e.g., less time wasted on idle discussion. The second most common response was that information should be shared earlier and not by word of mouth (c.f. Chapter $\mathrm{V}$ for recommendations). Subjects were also asked to express their opinions on the affects of the Medicare crisis on the quality of patient care.

While decision making is the focus of this paper, a secondary concern of this paper is to examine the issues of the quality of patient care. Nine of the twelve subjects responded during the interview that they thought the quality of patient care had decreased. These responses varied from, "a severe drop" in the quality of care, to only a "slight decrease" in the quality of patient care. Three of the twelve subjects thought that the quality of patient care had remained the same. Frequently, their rationale was that there is a distinction between quality of care and quality of life, e.g., the ensueing changes have not affected the overall quality of patient care, rather the quality of the patient's life.

Chapter $\mathrm{V}$ will focus on the conclusions that may be drawn from this data. It will also offer some suggestions for further research and recommendations for the dialysis program. 
CHAPTER V

CONCLUSIONS AND RECOMMENDATIONS

This final chapter contains the conclusions drawn from the results and analysis of this study by the author. This chapter further contains recommendations for both the Dialysis Program at GSHMC and for future research.

As noted in the previous chapter, the decision making practices of the GSH Dialysis Program were altered as a result of the Medicare crisis. It was not the purpose of this study to identify the specific decision making application(s) that were employed during the crisis period; rather, the purpose was to observe for a shift in member participation in the decision making process. It is evident that this dialysis program, whether by manipulation or by intuition, altered its decision making practices to a method that was perceived to be participative in spite of observations to the contrary. Further, it seems likely that the person or persons instigating this change in practice were those individuals with the power. Who then were the power holders during this period of crisis? The increase in the administrators perogative holds consistent with historical trend.

Paul Starr's treatise on the transformation of medicine in America tells of a constant struggle for 
power between the physician, and the hospitals and insurance companies. The Johnsonian Health Care packages of the 1960 's not only brought social reform for the health care system, it also began a period when the administration had the extra power needed to hold the upper-hand in this ongoing power struggle. Thus, these reforms allowed the physicians to control the hospital and insurance systems through their "medical expertise". This imbalance of power between physicians and hospitals/insurance companies has been relatively consistent until recently. Nowhere can this struggle be more evident than in a dialysis program in which there is joint decision making by its physicians and administrators. Further, it is fairly certain that this power scenario has not escaped the GSH Dialysis Program. As was seen in the comparison between the two periods on the Decision Ranked as Most Important from the survey (Figure 2), there was a distinction in what was perceived as the important issues or topics. During Period I, pre-crisis, the issues were primarily medical; however, Period II or post-crisis issues were almost exclusively of an administrative/business nature. It may be concluded that this immediate Medicare crisis induced by the Reagan administration has created a counter-balance in the power struggle. Those people in administrative positions or who possess a strong business acumen have been granted an edge 
in the power struggle by the definition of the crisis. It can be stated with great certainty that this shift in power will continue as a result of the inevitable continued Medicare cutbacks accompanying President Reagan's re-election. The Good Samaritan Dialysis Program is no exception, and it too will experience the organizational pains of a shift of power.

Perhaps it was the quiet transformation of the power of the decision makers in the GSH program which allowed them to prevail through this Medicare crisis. The administrators, physicians, and managers of the GSH Dialysis Program are to be commended for their use of a decision making method suited to solve the crisis. This approach allowed for a truly holistic way to address their problems. First, by having open involvement of all members there was a relatively surprise-free work environment. Second, because the environment was a supportive one, members shared their knowledge openly. Third, the dynamics of the crisis and the overall participative approach directed the members (including staff) toward systematic goals, i.e., a common cause. Fourth, there was a sense of giving and getting collaboration in an air of optimism. Last and most important, there was constant feedback by everyone involved. This program is to be congratulated for working 
through the crisis and keeping the "big picture". For truly the "big picture" is the recognition of the need to relate to others.

Recommendations for the GSH Dialysis Program

When asked what could be done to improve the decision making practices of the program, most of the subjects responded, "better meeting management". Because health care is undergoing a financial crisis, medical programs must adopt a business perspective if they are to be competitive and remain in the market. Decision making meetings must be approached with this same business orientation. The decision making meetings of the Dialysis Program need direction, i.e., who is and should be meeting, and what are the objectives of the meeting. Since the decision making meeting is problem-centered, that time should not be used for informing or reporting. Meeting time is precious and should not be wasted on informing the participants; rather, information should be shared prior to the meeting. Most importantly the meeting should be held to a schedule and kept to the objectives. Many other factors are important in running a "good" meeting. 25 should some of these basics of meeting management be instilled in the program, the efficiency, direction and satisfaction with decision making 
process could only improve.

My second recommendation for this program is that it re-examine its method of organizational thinking. Every organization has its own mind and way of thinking, and thus there should be an explicit assigning of what Ben Heirs refers to as "thinking responsibilities". As the group or administrator makes assignments they should also specify "thinking requirements" and responsibilities. Group members should know the corporate mind and use it to guide their own thinking process. Further, the thinking responsibilities of a given position should be explicit in the job description, evaluations, and recruitment. For this corporate/program mind to remain healthy it needs to maintain a system for reviewing its thinking procedures and activities. 26 The combination of these steps will serve to further edify the employee of the Dialysis Program.

A third recommendation for the GSH Dialysis Program is that it preserve the spirit of the participative approach created during the crisis. Decision makers created for

25 For a review of a practical methodology of meeting management refer to Antony Jay, "How to run a meeting" (Boston: Mass., printed in HBR March-April, No. 76204, 1976), pp. 120-134.

26Ben Heirs and Gordon Pehrson, The Mind of the Organization (N.Y.: Harper \& ROW, Publ., 1982), pp. 70-86. 
themselves and their employees an open trusting environment born-out of a common cause, i.e., dealing with the immediate Medicare crisis and the future of the program. The participative approach promotes shared knowledge, systematic goals, a willingness to shift resources, a collaborative effort, optimism and constant feedback. By promoting a common cause within the Program, e.g., the future of the program or something even more immediate, the spirit of the participative approach will continue to strengthen. Wherein, decision makers at the top will not only have the support of their subordinates, but it will be easier to enact the eventual changes needed to accommodate the evolving health care market.

The final recommendation for this dialysis program is that the decision makers be responsible. Many of the problems faced by the program may be solved by one person or just a few individuals. Decision makers need to be responsible and make some decisions without group consensus. Regardless of whether a decision is made by one person or a large group, each individual is answerable to his own conscience. It is not only a waste of time to address every issue through the group, it connates a lack of decisiveness and perspective on the part of administrators. Some decisions require a collective effort and others do not. The overall decision making process may be far more 
fruitful if problems are evaluated for the need to be addressed by more than one person. As servants of the public, the decisions made by the decision makers of this program should reflect the morality of the community they serve.

Recommendations for Further Research

Because this is a case study and examines only one organization, it is not known how other dialysis programs responded to the Medicare crisis. Did the decision makers in other similar programs alter their decision making practices to become more participative? If so, was it perceived as being effective in dealing with the ensuing changes? Can it be concluded from analysis of other programs that physicians are losing power to the administrators? Should analysis of other programs deliver reliable data by applying the characteristics of the program to the Decision Making continuum, were these characteristics similar to those exhibited by the GSH program?

Further research on decision making employing the use of a participative decision making continuum is needed to support the reliability and validity of this method. In addition, the development of an empirical method to demonstrate a change in decision making practices during periods of crisis, change, and/or uncertainty is desired to 
further verify the presence of such a change. Such a method may be developed by attaching numerical parameters to the responses of the questions in the Decision Making Survey. While the follow-up interview will still allow for an in-depth analysis of the decision making process.

Lastly, although extensive analysis of decision making applications for the health care setting have been conducted, there has as yet not been an approach developed specifically for the dialysis administrative or clinical context. Although preliminary analysis indicates that a multiattribute or group utility function decision making method may be applicable to this setting.

In conclusion, the problems addressed by this study are of immediate concern and great importance for discerning decision strategies for the dialysis and health care market. If programs are to survive this stage in the transformation of medicine, they will do so by being proactive decision makers. Decision makers who are conscious of the "big picture" and can adapt to the rising pressures of a cost conscious public are certain to be the survivors of this transition. 


\section{A SELECTED BIBLIOGRAPHY}

1. Anderson, Barry, Donald Deans, Kenneth Hammond, and Gary McClelland. Concepts in Judgment and Decision Research (N.Y.: Praeger Publishers, 1982).

2. Argyris, Chris. Interpersonal Competence and Organizational Effectiveness (Homewood, Ill: The Dorsey Press Inc., 1962).

3. Azumi, Koya and Jerald Hage. Organizational Systems (Lexington, Mass.: D.C. Heath, 1972).

4. Barclay, Scott, et. al. Handbook for Decision Analysis (McLean, Virginia: Decisions and Designs, Inc., 1977).

5. Blau, Peter and Richard Schoenherr. The structure of Organizations (N.Y.: Basic Books, Inc., 1971).

6. Bovbjer, Randell, Phillip Held, Mark Pauly. Pro-Competitive Health Insurance Proposals and Their Implications for Medicare's End Stage Renal Disease Program (Wash. D.C.: The Urban Institute, Research Paper, 1982).

7. Brozovich, John and Donald Luftus. "PhysicianAdministrator Decision Making for High-Technology Purposes: A Model Approach." (Health Care Management Review, Vol . 6, No. 3, Summer 1981, pp. 63-73).

8. Collins, B.E. and H. Guetzkow. A Social Psychology of Group Processes for Decision Making (London: John Wiley \& Sons, Inc., 1964).

9. Collins, Lyndhurst. The Use of Models in the Social Sciences (Colorado: Westview Press, Inc., 1976).

10. Connor, Patrick E. Organizations: Theory and Design (CA: Science Research Associates, Inc., 1980).

11. Cyert, Richard M. and James March. Behavioral Theory of the Firm (N.J.: Prentice-Hall, Inc., 1963).

12. DuBrin, Andrew. Casebook of Organizational Behavior (N.Y.: Pergamon Press, 1977). 
13. Duncan, R.B. "Characteristics of Organizational Environment and Perceived Environmental Uncertainty." (Administrative Science Quarterly, Vol. 17, 1972).

14. Ebert, Ronald and T. Mitchell Organizational Decision Processes (N.Y.: Crane, Russak and Co., Inc., 1975).

15. Fisher, B. Aubrey. Small Group Decision Making:

Communication and Group Process. (N.Y.: McGraw-Hill Book Co., 1974).

16. Goldhaber, Gerald M. Organizational Communication (Dubuque, Iowa: William C. Brown Co. Publishers, 1979).

17. Gordon, Raymond. Interviewing: Strategies, Techniques and Tactics. (Illinois: The Dorsey Press, 1980).

18. Greiner, L.E. "Patterns of Organizational Change" (Harvard Business Review, Vol. 45, No. 3, 1967).

19. Hall, Richard H. Organizations' Structure and Process (N.J.: Prentice-Hall, Inc., 1982).

20. Heirs, Ben and Gordon Pehrson. The Mind of the Organization (N.Y.: Harper \& Row Publishers, 1982).

21. Heller, Frank A. Leadership Decision Making and Contingency Theory (Industrial Relations, Vol. 12, No. 2, May 1973).

22. Horowitz, Ira. Decision Making and the $T$ heory of $T$ he Firm (N.Y.: Hold, Rinehart, \& Winston, Inc., 1972).

23. Jay, Antony. "How to run a meeting." (Boston: Mass., printed in HBR March-April, No. 76204, 1976).

24. Jones, Diane. Group Progress: Recognizing and Removing Barriers (Virginia: National School Public Relations Assoc., 1978).

25. Kanter, Rosabeth M. The Change Masters (N.Y.: Simon \& Schuster, Inc., 1983).

26. Kaplan, Martin and S. Schwartz. Human Judgment and Decision Processes in Applied Settings (N.Y.: Academic Press, Inc., 1977) . 
27. Katz, Daniel and Robert L. Kahn. The Social Psychology of Organizations (N.Y.: John Wiley \& Sons, Inc., 1966).

28. Kerr, Steven et. al organizational Behavior. (Columbus, Ohio: Grid Publishing, Inc., 1979).

29. Krischner, Jeffrey. "An Annotated Bibliography of Decision Analytic Applications to Health Care." (Operations Research, Vol. 28, No. 1, 1980, pp. 97-113).

30. March, James and John Olsen. Ambiguity and Choice in Organizations (N.Y.: Columbia University Press, 1982).

31. and Herbert Simon. Organizations (N.Y.: John Wiley \& Sons, Inc., 1958).

32. Michnich, Marie, Stephen Shortell, and William Richardson. "Program Evaluation: Resource for Decision Making." (Health Care Management Review, Vol. 6, No. 3, Summer 1981, pp. 25-35).

33. Odiorne, George S. The Change Resisters (N.Y.: Prentice-Hall, Inc., 1981).

34. Pace, R.W. and R. Boren. The Human Transaction (Glenview, Ill.: Scott Foresman, Publishers, 1973).

35. Parsons, Talcott. "The Analysis of Formal Organizations", Structure and Process of Modern Societies (N.Y.: Free Press, 1960).

36. Rosenfeld, L.B. Human Interaction in the Small Group Setting (Columbus, Ohio: C. Merrill, 1973).

37. Rubinstein, Moseh F. and Kenneth Pfeiffer. Concepts in Problem Solving (N.J.: Prentice-Hall, Inc., 1980).

38. Starr, Paul. The Social Transformation of American Medicine (N.Y.: Basic Books, Inc., 1982).

39. Stempel, Guido and Bruce Westley. Research Methods in Mass Communication (N.J.: Prentice-Hall Inc., 1982).

40. Steward, Larry. Attitudes Toward Communication: The Content Analysis of Interviews with Eight Reticent and Eight Non-Reticent College Students (Penn. State University, PhD Dissertation, 12/68). 
41. Thompson, James. Organizations in Action (N.Y.: McGraw-Hill Book Co., 1967).

42. Tucker, Raymond, Richard weaver, Cynthia Berryman-Fink. Research in Speech Communication (N.J.: Prentice-Hall Inc., 1981).

43. Weber, Max. The Theory of Social and Economic Organizations, trans. A. Henderson and Talcott Parsons (N.Y.: Oxford Univ. Press, 1947).

44. William, Anthony P. Participative Management (Reading: Mass.: Addison-Wesley, Publ., 1978).

45. Zald, Mayer. Organizational Change: The Political Economy of the YMCA (Chicago: Univ. of Chicago Press, 1970). 


\section{APPENDIX A}

\section{DECISION MAKING SURVEY}

In 1972 Congress extended Medicare to all victims of End Stage Renal Disease (ESRD) regardless of age. During the 1970 's and early $1980^{\prime} \mathrm{s}$, the program relied on a combination of cost-based reimbursements and Medicare-fixed fee assessments, or "screen" charges, as the mechanism for regulating payment and care. In 1981 the Health Care Finance Administration mandated changes in the mechanism and financing of the ESRD Program by the provisions of the Omnibus Budget Reconciliation Act (9735). These changes in Medicare law were eventually published in May 1983 in the Federal Register and became effective August 1, 1983.

This survey addresses the overall question of decision making in a Hospital Dialysis Program, and is divided into two sets of questions. The first set of questions pertain to problems/decisions dealt with prior to the August 1, 1983 effective date for Medicare changes. The second set of questions pertain to those problems/decisions addressed after the August 1983 effective date. 
In responsing to the questions in this survey, please recall, to the best of your ability, those decisions that were addressed from May 1983 through January 1984. It is important that all items in this survey be completed. Please note that the purpose of this survey is to collect data on decision making. All names and infomration provided will be held in strictest confidence; further, participants names will be disguised in the final printing. YOUR NAME 
1. The following are problems/decisions identified by the meeting minutes of the Dialysis Management Council Group. From your point of view rank these decision in order of their importance.

1. Communication problems regarding hospital admissions/discharge procedures.

2. L__ Leasing/renovations of an outpatient facility.

3. Change in peritoneal dialysis protocol.

4. Change in billing method for home patients.

5. Resolution of a clear financial statement.

6. L__ Long term facility planning.

7. Changing protocol for patient travel.

8. Change in protocol and responsibility for medications.

9. Dialyzer re-use project and protocol.

10. Transplantation transfusion protocol.

11. Closure of Acute Unit night shift.

12. L__ Loss of patients to another facility.

13. Hiring a consultant to help deal with the upcoming Medicare changes.

14. ___ Treatment of AIDS patients.

15. Reorganization of dialysate delivery system.

16. __ New Code System for Outpatient Unit.

17. __ OTHER as identified by you: 
14. How would you rate the level of conflict surrounding this decision, i.e., between those people making the decision (circle one).

HIGH FREQUENT MODERATE LOW NONE

15. Was this conflict a GOOD BAD INDIFFERENT (circle one) influence on the final solution.

16. How many people were involved in reaching a solution (circle one).

$\begin{array}{cllll}\text { ONE OR } & \text { SMALL } & \text { LARGE } & \text { DEPARTMENT } & \text { ENTIRE } \\ \text { TWO } & \text { GROUP } & \text { GROUP } & & \text { ORGANIZATION }\end{array}$

17. The following are those problems/decisions identified by the meeting minutes of the Dialysis Management Council Group from the period of August 1983 through January 1984. From your own point of view rank these decision in order of their importance.

1. Interpretation of the new Medicare changes, i.e., the Dialysis Reimbursement Schedule.

2. N_ Need and methods of improving efficiency and reducing personnel as a result of Medicare changes, i.e., change of staffing and scheduling.

3. A backlog of peritoneal patients in the hospital.

4. Problems associated with the dialyzer re-use program.

5. Deletion of "special" dialysate baths from those offered as a time conservation measure.

6. Responses and actions taken as a result of the 1982 Network Coordinating Council \#2 publication on ESRD.

7. Resolution of defective water treatment units.

8. N_ Need for a new protocol for patients with confirmed non-A/non-B Hepatitis.

9. N__ Need for a new billing procedure as a result of the Medicare Dialysis Reimbursement Schedule.

10. OTHER as identified by you: 
Instructions:

Answer the following questions on the basis of the decision which you identified as the most important in the above Question \#17.

2. How much time would you estimate it took to reach this solution (hours, days, weeks)

3. Was the decision made formally or informally (circle one).

4. Who phrased the final solution for the first time (person's name)

How did you interpret this statement, positively or negatively (circle one).

5. Did you identify with a particular position or point of view on this issue? Yes or No (circle one).

6. Did you feel that your view was included in the final solution? (circle one)

ALL MOST SOME A LITTLE NONE of your view was included

7. Were you given access to information you felt you needed to contribute to the decision? (circle one) ALL MOST PARTIAL SELECT NONE

8. How did you as an individual feel about the decision, i.e., the final outcome.

EXCEPTIONAL GOOD SATISFACTORY POOR WASTE OF TIME

9. Would like to have had more, the same, or less (circle one) input on this problem?

10. Should you have had more, the same, or less (circle one) input?

11. Were there communication channels or processes involved in reaching the final solution which you did not have access to? Yes or No (circle one).

12. Do you thing the other individuals involved in this decision felt that their view was included in the final solution? (circle one)

ALL MOST SOME A LITTLE NONE of their view was included 
13. How did you feel about the method used in reaching a solution (circle one). EXCEPTIONAL GOOD SATISFACTORY POOR WASTE OF TIME

14. How would you rate the level of conflict surrounding this decision, i.e., between those people making the decision (circle one). HIGH FREQUENT MODERATE LOW NONE

15. Was this conflict a GOOD BAD INDIFFERENT (circle one) influence on the final solution.

16. How many people were involved in reaching a solution (circle one). ONE OR

TWO
SMALL GROUP
LARGE GROUP
DEPARTMENT

ENTIRE ORGANIZATION 


\section{APPENDIX B}

\section{DECISION MAKING INTERVIEW TOPICS}

1. Subjects throughts/feelings about the survey, e.g., did the survey help you gain some insight into how decisions are made in this department or did you feel it was a waste of time.

2. Subject's thoughts/feelings about being interviewed, e.g., are there certain aspects about how decisions are made that you would rather not discuss or you feel are not appropriate for this discussion.

3. a. How did the subject feel about the decisions made during each of the two periods, i.e., positive or negative.

b. What did the subject think the rest of the department felt about the decisions made during each period.

4. Subject's thoughts/feelings about the frequency of unconstructive conflict during each of the two periods, e.g., do you think that the decision made during Period One or Period Two involved more unnecessary conflict. What sort of conflict issues stick out in your mind. 
5. Which period did the subject feel it took more time to reach decisions and why.

6. Does participatory management increase the quality of the final decision, e.g., does having more people involved in the decision making process result in a better decision.

7. Subject's perception of the effectiveness of the formal communciation system, e.g., are the formal channels of communication generally adhered to or is the majority of the actual communication/problem solving activity accomplished through an informal network.

8. Do subject's perceive a greater availability of information from one period over the other; if so, is it thought that the period with greater information availability produced better results because of that information.

9. Do subject's perceive that the decisions made during the crisis period have had an impact on the quality of patient care.

10. Subject's thoughts on how or what could be done to improve the decision making process. This was proposed as an open ended question. 